\title{
PREPARATIVE HIGH-PERFORMANCE LIQUID CHROMATOGRAPHIC SEPARATION OF INDIVIDUAL AMINO ACIDS DERIVED FROM FOSSIL BONE COLLAGEN
}

\author{
GERT JAAP VAN KLINKEN ${ }^{1}$ and WILLEM G MOOK
}

\author{
Centrum voor Isotopenonderzoek, State University of Groningen \\ Westersingel 34, 9718 CM Groningen, The Netherlands
}

\begin{abstract}
Extracting a series of amino acids from fossil "collagen" makes it possible to compare chemically wellcharacterized molecules from one bone sample, both chemically and by isotopic analysis. Thus, the integrity of collagen samples and possible contamination can be checked. We describe the routine high-performance liquid chromatographic extraction of five amino acids: glycine, hydroxyproline, glutamate, threonine and alanine. Humates are eliminated during the extraction, which can be monitored continuously.
\end{abstract}

\section{INTRODUCTION}

Conventional methods of ${ }^{14} \mathrm{C}$ bone dating and paleodietary stable isotope research often lead to ambiguous results due to problems in extracting uncontaminated, unaltered bone collagen from degraded bone (eg, Longin 1971; Olsson et al 1974; El-Daoushy, Olsson \& Oro 1978; Taylor 1980, 1987).

We do not fully understand the collagen degradation process during bone diagenesis (Schwarcz, Hedges \& Ivanovich 1989; Stafford, Brendel \& Duhamel 1988; Gillespie 1986; Hedges \& Law 1989), and the changes in bones in the soil are as diverse as the specific circumstances to which they were exposed during their burial. Descriptions of collagen preservation are inadequate for describing alterations in a fossil bone "collagen" sample, at least at the molecular level.

Extracting collagen from fossil bone in the form of gelatin (denatured, unfolded collagen) is not a totally selective process (Gurfinkel 1987; Taylor 1980; Gillespie, 1986; Stafford, Brendel \& Duhamel 1988). Isotope analysis of fossil bone gelatin depends on mass balance and isotopic differences between endogenous (and isotopically unchanged) collagenous material and other materials that attach to it during diagenesis. These materials (eg, humics) can be exogenous or formed in situ from collagen parts and may or may not be isotopically different from the original collagen fiber.

Thus, the state of preservation of fossil "collagen" is crucial for accuracy in the resulting isotopic analyses (Stafford, Brendel \& Duhamel 1988). A better chemical characterization of the fraction selected for dating would be the first step in improving the validity of both bone dating and paleodietary analysis. This means using distinct molecules such as amino acids or specific proteins rather than insoluble residues. For radiocarbon dating, this possibility has come within reach since the development of accelerator mass spectrometric (AMS) ${ }^{14} \mathrm{C}$ detection. AMS requires a very small sample: milligram quantities instead of grams, required for conventional radiocarbon dating (Mook 1984). At present, some researchers prefer to extract larger or smaller (peptide) parts of collagen (Brown et al 1988; DeNiro \& Weiner $1988 \mathrm{a}, \mathrm{b}$ ), or other bone proteins (Gillespie 1989). Others extract a mixture of amino acids from "collagen" (Ho, Marcus \& Berger 1969; Stafford et al 1987; Hedges et al 1989), or one or two specific amino acids, eg, hydroxyproline and proline (Wand 1981; Stafford et al 1982;

${ }^{1}$ Present address: Radiocarbon Accelerator Unit, 6 Keble Road, Oxford OX1 3QJ, UK 
Gillespie \& Hedges 1983; Gillespie, Hedges \& Wand 1984), or a series of individual amino acids (Hare \& Estep 1983; Macko et al 1983; van Klinken 1989).

We describe here routine extraction of five individual amino acids from collagen hydrolyzates (glycine (Gly), glutamate (Glu), hydroxyproline (Hyp), threonine (Thr) and alanine (Ala)) by means of high-performance liquid chromatography (HPLC).

\section{AMINO ACIDS AND ISOTOPE CHEMISTRY}

\section{Collagen Amino Acids}

Biochemically intact bone collagen contains 18 different amino acids (Table 1). Not all amino acids are of equal interest in an isotopic comparison, nor can they be isolated in an equally routine way with the described HPLC system; thus, we must select carefully amino acids for routine analysis.

TABLE 1

The amino acid composition of undegraded collagen

\begin{tabular}{llc}
\hline Amino Acid & Abbr & Residues \%o \\
\hline Hydroxyproline* & Hyp & 101 \\
Aspartate & Asp & 51 \\
Threonine*** & Thr & 18 \\
Serine & Ser & 35 \\
Glutamate* & Glu & 75 \\
Proline & Pro & 116 \\
Glycine* & Gly & 317 \\
Alanine* & Ala & 113 \\
Valine** & Val & 19 \\
Methionine & Met & 5 \\
Isoleucine** & Ile & 13 \\
Leucine** & Leu & 28 \\
Tyrosine & Tyr & 5 \\
Phenylalanine** & Phe & 18 \\
Hydroxylysine & Hyl & 5 \\
Lysine** & Lys & 24 \\
Histidine** & His & 5 \\
Arginine & Arg & 49 \\
\hline * Amino acid selected for investigation & \\
** Essential amino acid & &
\end{tabular}

The amino acids Hyp and hydroxylysine (Hyl) are typical for collagen. Hyp and Hyl are not incorporated in the polypeptide chains of collagen by the usual mechanisms of protein synthesis. Some specific proline (Pro) and lysine (Lys) residues are hydroxylated in situ after they are already incorporated in the $\alpha$-chain, the building block of collagen fiber. Hyl is important because carbohydrate units, mostly a disaccharide of glucose and galactose, become attached to it during collagen synthesis (glycosylation). Hyp is indispensable for the stabilization of the collagen superhelix because it increases the stability of the molecule by hydrogen bonding (Ramachandran \& Reddi 1976); insufficient hydroxylation of Pro in living 
bone occurs during scurvy. In collagen, Hyp accounts for ca $10 \%$ of the amino-acid residues; otherwise it occurs only in very low amounts. Because of this high bone-specificity, Hyp was recognized as an ideal dating sample at an early stage in the development of AMS (Wand 1981).

Based on biosynthetic relationships, carbon and nitrogen isotopic ratios in Glu, Pro and Hyp, as well as in Lys and Hyl must be identical, on average. The isotopic comparison of these amino acids could provide a test for contamination of fossil collagens. Unfortunately, the Hyl content of collagen is very low: ca 5 residues per 1000, which makes routine preparative isolation difficult. Hyp and Glu can easily be isolated (Fig 1), but Pro requires an extra buffer in the HPLC separation (Table 2).

Many amino-acid transamination reactions (involving a transfer of nitrogen from one amino acid to another) are known in animal biosynthesis, which could bring about other possibilities for ${ }^{15} \mathrm{~N} /{ }^{14} \mathrm{~N}$ ratio comparison of different amino acids. For example, nitrogen is transferred from Glu to almost any other L-amino acid. Most probably, these amino acids are all isotopically lighter in nitrogen than Glu because of isotope effects during transamination (Macko et al 1987). Glu is the most abundant amino acid in nature, and fossil bone Glu is likely to be contaminated very easily with exogenous Glu. For this reason, Glu seems to be an ideal amino acid to test overall bone contamination.

Glycine (Gly), the smallest amino acid, accounts for one-third of the residues in collagen. Serine (Ser) is the precursor of Gly. Gly can be separated easily; in the case of Ser, an extra extraction run of $45 \mathrm{~min}$ is needed at a higher column temperature. A collagen molecule is likely to be largely deteriorated if a severe contamination with exogenous Gly appears to exist, indicated by deviating Gly concentrations and stable isotopic ratios. Consequently, all other isotopic measurements should be treated with caution.

The amino acids mentioned so far are non-essential, ie, they can be synthesized by the animal itself; Thr is one of the essential amino acids (Table 1): it has to be taken up with food. Thus, ${ }^{13} \mathrm{C} /{ }^{12} \mathrm{C}$ and ${ }^{14} \mathrm{C} /{ }^{12} \mathrm{C}$ isotope ratios of Thr relate to those of dietary Thr. On the other hand, ${ }^{15} \mathrm{~N} /{ }^{14} \mathrm{~N}$ values appear to be slightly lower than those of dietary Thr, perhaps because of a preferential incorporation of ${ }^{14} \mathrm{~N}$ containing Thr (Gaebler, Vitti \& Vukmirovich 1966).

Gly concentrations are often low in fossil bone samples, along with higher concentrations of valine (Val), isoleucine (Ile), leucine (Leu) and phenylalanine (Phe), and probably of Thr and Ser (Dungworth et al 1974).

\section{Amino-Acid Separations}

One aspect of modern chromatographic separations has been underestimated: the importance of detecting the molecules we want to extract and possible contaminants during the isolation process. On-line detection allows us to continously monitor the quality of each separation, and register each deviation. This can be done with HPLC, which yields a highresolution separation together with excellent reproducibility in a relatively short time $(2 \mathrm{hr})$. A preparative (milligram-scale) system with a low ${ }^{14} \mathrm{C}$ background is needed for use in natural abundance isotope chemistry, essentially without memory or isotopic fractionation effects.

Most of the chromatographic amino acid separation methods are designed for analytical (nanomole level) use: either ion-exchange analyzers (Moore \& Stein 1951) or reversed phase systems (eg, Joseph \& Marsden 1986) with organic buffer systems and post- or precolumn derivatization. These do not suit the specific demands of fossil bone isotopic analysis. Carbon contamination from the organic buffers and derivatization reagents is difficult to avoid. For instance, ninhydrin derivatization reagent turned out to be severely contaminated by ${ }^{14} \mathrm{C}$ (up to 
10 times the activity of recent natural carbon), possibly because of contact with labeling compounds during manufacturing. The main disadvantage, however, is the fact that nonaminated contamination cannot be detected if derivatization techniques are used. For these reasons, we used direct UV detection at $210 \mathrm{~nm}$.

Spectrophotometric detection is based on the measurement of the absorbance of monochromatic light by the sample in accordance with the Lambert-Beer law:

$$
\mathrm{c}=\left[\log \mathrm{I}_{0} / \mathrm{I}_{\mathrm{t}}\right] / \varepsilon . \mathrm{L}
$$

where $\mathrm{c}=$ concentration of unknown solution; $\mathrm{I}_{0}=$ intensity of the incident light of the used wave length (ie, $210 \mathrm{~nm}$ ); $\mathrm{I}_{t}=$ intensity of the transmitted light; $\log \mathrm{I}_{0} / \mathrm{I}_{t}$ being the absorbance A (formerly called extinction $\mathrm{E}$ or optical density $\mathrm{D}$ ); $\varepsilon=$ molar absorbtion coefficient (formerly the extinction coefficient), dependent on the type of solvent, wave length and temperature; $\mathrm{L}=$ path length of light through solvent.

Spectrophotometric detectors provide an output in absorbance units which is linearly related to sample concentration over a range of $10^{5}$.

Baseline separation of amino acid peaks is indispensable for avoiding partial mixing of fractions, especially if we inject large amounts of sample. In fact, complete separation is not obtainable for all "collagen" amino acids, due to the complexity of the amino acid / "humics" mixture; thus, some of the amino acids have to be omitted.

We built an HPLC system with an inorganic buffer system, a cation exchange (sulphonated resin) column, and direct UV detection at $210 \mathrm{~nm}$. We separated amino acids with one buffer solution during a run of $145 \mathrm{~min}$ at a maximum load of $100 \mathrm{mg}$ of hydrolyzate. We can extract aspartate (Asp) and Ser in a separate run using a higher column temperature. An optional buffer for the separation of Pro, Val, Leu, and histidine (His) is available. We also can isolate some humic fractions and unhydrolyzed parts of collagen chains (peptides) if they are present.

Normally, we then analyze amino acids for their stable isotope content $\left({ }^{13} \mathrm{C} /{ }^{12} \mathrm{C},{ }^{15} \mathrm{~N} /{ }^{14} \mathrm{~N}\right)$ to determine the optimal amino acids for dating. The chosen amino acids finally can be ${ }^{14} \mathrm{C}$ dated by means of AMS.

\section{MATERIALS AND METHODS}

\section{Sample Selection}

As discussed above, the state of collagen preservation determines the quality of isotope results (see also Stafford, Brendel \& Duhamel 1988). The choice of bone or part thereof can be crucial. We prefer dense bones, such as the shafts of long bones, over more porous ones. We obtained especially good results from dental elements, even from tropical soils where bone withers quickly. Both bone and dentin contain the same type of collagen (Type I, Bornstein \& Traub 1979); however, the initial collagen content is higher in dentin (30\% compared to ca $15 \%$ in bone), and dentin is much denser than bone. We found no differences in isotope content between bone and teeth (van Klinken et al, ms).

\section{Mechanical Cleaning of the Bone Sample}

At first, we remove the bone surface, or we saw out a dense, unexposed section of the inner part of the bone. The selected material is ground to $0.5-1.5 \mathrm{~mm}$ particles in a ball or chopping mill, making sure that the bone powder does not overheat. 


\section{Demineralization}

We subsequently decalcify the bone powder in dilute hydrochloric acid $(3 \% \mathrm{HCl}$ in doubly distilled water) at $4^{\circ} \mathrm{C}$, stirring, adding $10 \mathrm{ml}$ aliquots of dilute acid until degassing stops. During demineralization, some of the collagen fibers will hydrolyze and become soluble if the temperature is too high or demineralization time is too long (Longin 1971; Brown et al 1988), and are then lost for the following gelatinization step. Demineralization time must be optimized for these opposing reactions. Under the described circumstances, the demineralization process lasts for $4-10 \mathrm{hr}$. After repeated centrifugation and washing with distilled water, the residue is used for gelatinization. However, in the smallest samples, the residue may not contain enough gelatin, in which case, the use of supernatant "collagen," the dilute acid-soluble fraction, is sometimes necessary.

\section{Gelatinization}

Collagen fibril structure is lost during prolonged heating at temperatures higher than $58^{\circ} \mathrm{C}$, the denaturation temperature of collagen (Piez 1984). During gelatinization, collagen fibers are unfolded and become soluble, while impurities (humates or severely degraded collagen parts) remain in the residue and can be eliminated by centrifugation (Longin 1971). Although gelatin extraction is not as selective as it once was thought to be (Gurfinkel 1987; Stafford et al 1987), it is still useful for improving the purity of fossil "collagen." The residue from the demineralization is placed in a shaking incubator at $75^{\circ} \mathrm{C}$ and a $\mathrm{pH}$ of ca 3 for 0.5 to $2 \mathrm{hr}$ in closed glass containers. The steady movement speeds up the gelatinization process and improves the yield. Minimizing gelatinization time, temperature and air contact during the process prevents caramelization of the gelatin's carbohydrates, which appears as an increasingly yellow solution, and which could make the gelatin less accessible to further amino-acid extraction. The supernatant, containing the gelatin, is then freeze dried.

\section{Hydrolysis}

The gelatin is hydrolyzed in doubly distilled $6 \mathrm{~N} \mathrm{HCl}$ (Suprapur, Merck; 3ml per 100mg of gelatin) for $20 \mathrm{hr}$ at $110^{\circ} \mathrm{C}$ in sealed ampules. A part of the gelatin (up to $25 \%$ ) is not hydrolyzed and remains a brown, insoluble residue. Experiments with higher temperatures, stronger acid, lower gelatin concentration and longer hydrolysis times failed to give better amino acid yields. Perhaps it is the more degraded part of the gelatin that is not, or only partially, sensitive to hydrolysis. Based on the differences in stable isotopic ratios between this residue and the intact "collagen," Hare and Estep (1983) suggest that the residue is a diagenetic product from lipids or carbohydrates from the glycosylated residues of the collagen fiber.

After hydrolysis, the sample is evaporated to dryness in a desiccator; subsequently, the amino acid mixture is redissolved in doubly distilled water, in a maximum concentration of ca $100-120 \mathrm{mg}$ hydrolyzate per $1000 \mu \mathrm{l}$. After centrifugation for $30 \mathrm{~min}$ at maximum speed, the hydrolyzate is ready for injection into the HPLC system.

\section{Amino-Acid Separation}

The HPLC system is designed to handle samples in an automated or semi-automated way, in amounts sufficient for stable isotope analysis or radiocarbon dating $(80-100 \mathrm{mg}$ of hydrolyzate). The system comprises a HPLC pump, a dead-volume injector with 
interchangeable sample loops, a chromatographic column with waterbath heating, a variable wavelength UV detector, and a fraction collector, which also controls the stepwise gradient. The extraction system is kept in an overpressure dust-free room. The (semi-) preparative HPLC pump must be able to deliver buffer flows of at least $20 \mathrm{ml} \cdot \mathrm{min}^{-1}$; the stainless steel connecting tubing is $0.16 \mathrm{~cm} \mathrm{OD,} 0.051 \mathrm{~cm}$ ID $\left(1 / 16^{\prime \prime} \times 0.020 "\right)$. The preparative $22 \times 500 \mathrm{~mm}$ column contains sulphonated cation exchange resin, Alltech Rogel-S (10 $\mu \mathrm{m}$ particle size). The column is heated by a waterbath/circulation system with a tolerance of $0.5^{\circ} \mathrm{C}$. Coiled nickel tubing, $40 \mathrm{~cm}$ long, is placed in front of the column to improve heat transfer to the solution. Directly after the column, the solution is water-cooled to $30^{\circ} \mathrm{C}$ using another $40 \mathrm{~cm}$ piece of coiled nickel tubing. Normally, the injection valve is fitted with a $1000 \mu \mathrm{l}$ sample loop, and is thoroughly cleansed with a detergent solution and doubly distilled water before each injection to prevent cross-contamination. We used a LKB 2151 variable wavelength UV-Vis detector at $210 \mathrm{~nm}$, fitted with a preparative flow-cell. A Gilson 201 fraction collector is used to collect fractions automatically (with peak/baseline detection) or manually, and to control the buffer change-over valves. Chemicals are pa grade; the de-ionized water is filtered and de-aerated in a vacuum filter system (filters $0.45 \mu \mathrm{m}$, Millipore); and buffer solutions are continuously flushed with helium.

The separation of the amino acid peaks is optimized using Sigma L-amino-acid probes until retention time and peak shape of each amino acid give a baseline separation at preparative loads and at 0.04 AUFS (Absorbance Units Full Scale) of the UV detector sensitivity. We checked amino acid purity by classical amino analysis: purity of amino acid fractions, isolated under the described elution conditions did not differ from the pa Sigma amino acids (for a summary of the elution conditions, see Table 2). We quantify the content of each amino acid in a sample using Sigma Collagen Standard mixture.

The entire amino acid elution sequence is different from the classical sequence of aminoacid analyzers, but we have found no explanation for this phenomenon.

TABLE 2

Elution conditions during preparative separations

\begin{tabular}{ll}
\hline Buffer flow rate & $18.01 . \mathrm{min}^{-1}$ \\
Pressure & $36 \mathrm{bar}\left(\mathrm{at} 74.5^{\circ} \mathrm{C}\right)$ \\
Column & $22 \mathrm{~mm} \times 500 \mathrm{~mm}$ Rogel-S, Alltech \\
& $10 \mu \mathrm{m}$ particle size, 10nm pore size \\
& Temperature $74.5^{\circ} \mathrm{C}$ (increased to $80^{\circ} \mathrm{C}$ for Asp and \\
& Ser separation \\
& UV detection at $210 \mathrm{~nm}$ \\
& $($ Semi-) preparative flowcell \\
Detector & 0.04 or 0.08 AUFS (preparative load of $50-100 \mathrm{mg}$ \\
& collagen hydrolyzate) \\
& A $0.1 \mathrm{M} \mathrm{NaH} \mathrm{PO}_{4}+0.1 \mathrm{M} \mathrm{H}_{3} \mathrm{PO}{ }_{4} \mathrm{pH}=2.12\left(25^{\circ} \mathrm{C}\right)$ \\
& B idem; $\mathrm{pH}=4.50$ optional \\
Buffer system & C $.04 \mathrm{M} \mathrm{NaOH} \mathrm{cleaning} \mathrm{and} \mathrm{column} \mathrm{regeneration}$ \\
& Stepwise; duration from moment of injection: \\
& A 100 min; $(\mathrm{B} 30$ min); C 15 min; A 30 min \\
\hline
\end{tabular}


Isotope fractionation occurs during the chromatographic separation; we have observed $\delta^{13} \mathrm{C}$ differences of maximally $50 \%$ between the first and the last parts of a Gly peak (cf Macko et al 1987). To overcome this effect, we collected complete baseline separated peaks with small baseline parts before and after the peak. The resulting average variation in Gly, the smallest amino acid, and consequently the most susceptible to isotopic fractionation (Macko et al 1987), is $\pm 0.5 \%$ for $\delta^{15} \mathrm{~N}$ and $\pm 0.4 \%$ for $\delta^{13} \mathrm{C}$.

The ${ }^{14} \mathrm{C}$ background is presently found to be lower than corresponding to $37,000 \mathrm{BP}$, with $>50,000 \mathrm{BP}$ collagen as a testing material.

\section{Desalting}

The buffer phosphate salts in the collected HPLC fractions destabilize the combustion for isotope analysis by creating a fluctuating carbon background in the oxygen flow combustion system. Therefore, the amino acids are desalted by elution of the fractions over a $1.8 \times 40 \mathrm{~cm}$ column of AG 11 A8 (Biorad), at a flowrate of $1 \mathrm{ml} \cdot \mathrm{min}^{-1}$. The salt-free amino-acid solution is then lyophilized.

Recently, we found buffer salts to give less problems using a $\mathrm{Cr}_{2} \mathrm{O}_{3}$ combustion system ( $\mathrm{CHN}$ analyzer), so we can omit desalting procedures in many of these combustions.

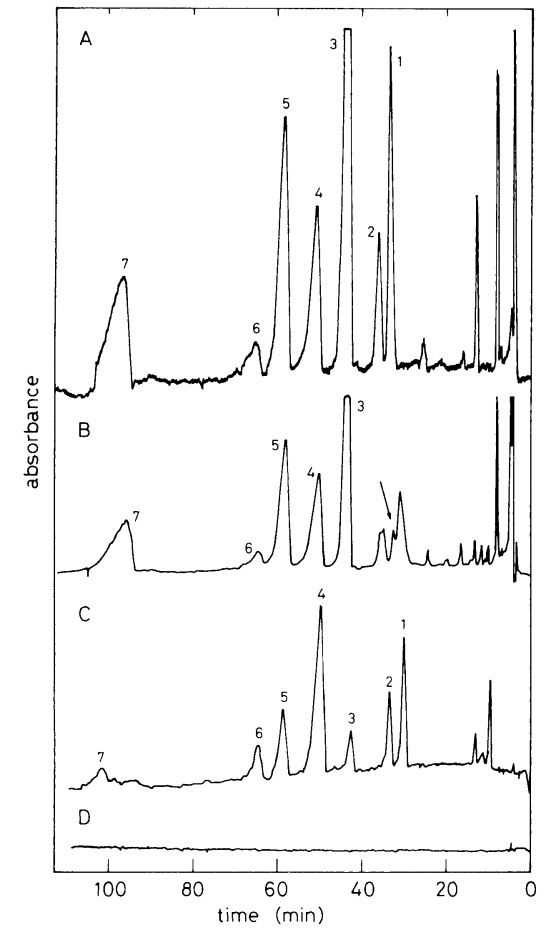

Fig 1A. A preparative separation (run \#478) of a fossil "collagen" CI $\left({ }^{14} \mathrm{C}\right.$ age $1700 \mathrm{BP}$ ), detector 0.08 AUFS. B. Preparative separation (run \#493) of "collagen" Malmok 15, Asp and Ser are deformed (arrow), detector 0.08 AUFS. C. Analytical run (\#494) of Sigma Collagen Standard, undiluted, $2.5 \mu \mathrm{mol}$ of each amino acid, except $12.5 \mu \mathrm{mol}$ Hyp, detector 0.02 AUFS. D. Blank run (\#453), 0.08 AUFS. Other elution conditions as described in Table 2. L-Amino acids: 1 Asp, 2 Ser, 3 Gly, 4 Hyp, 5 Glu, 6 Thr, 7 Ala.

\section{RESULTS AND DISCUSSION}

Figure 1 shows examples of HPLC separation chromatograms. In Figure 1A, a chromatogram of a preparative extraction of a "collagen" sample with an age of 1700 BP shows baseline separation of the five amino acids Gly, Hyp, Glu, Thr and Ala. Asp and Ser are not 
fully separated and thus cannot be used for isotopic analysis. Peaks during the first $30 \mathrm{~min}$ represent salts and humic fractions. Figure 1B shows irregularities in the shape of the Asp and Ser peaks, so that these amino acids should be treated with caution. Figure $1 \mathrm{C}$ is an analytical chromatogram of the reference material, Sigma Collagen Standard. Figure 1D shows a blank run.

Routine separation of individual amino acids from fossil bone removes all soil contaminants (eg, humates; Stafford, Brendel \& Duhamel 1988), except soil amino acids that have become attached to the bone collagen in situ during diagenesis. Free amino acids from the soil are washed out during gelatin preparation steps. Chemical bonding of exogenous amino acids can result in 1) a changed amino-acid composition (collagen differs considerably from the average protein), which can be detected during the HPLC separation, 2) in deviating stable isotope values of contaminated amino acids, which uncontaminated have characteristic isotopic compositions (Hare \& Estep 1983), or 3) in different ${ }^{14} \mathrm{C}$ ages of amino-acid fractions. These possibilities for identification of suspected samples will increase the quality of ${ }^{14} \mathrm{C}$ bone dating. However, wherever possible, ${ }^{14} \mathrm{C}$ dating of Hyp fractions should be preferred, because only Hyp is bone-specific to a high degree. All other amino acids occur in soils as well, and the sensitivity of chemical and stable isotope analysis is not sufficient to ensure correct ${ }^{14} \mathrm{C}$ ages. Therefore, individual ${ }^{14} \mathrm{C}$ measurements should be performed on these amino acids to distinguish between contaminated and uncontaminated fractions.

Macko et al (1983) separated individual amino acids using classic ion-exchange chromatography; unfortunately, they do not give many details of separation conditions. Hare \& Estep (1983) were the first to report isotope composition of collagen amino acids using this extraction system. The use of $\mathrm{HCl}$ as a volatile eluent facilitates collection of salt-free amino acids. It is not easy to use $\mathrm{HCl}$ in HPLC, so we choose a phosphate buffer system. Because these buffers are non-volatile, we needed to desalt fractions prior to combustion, introducing another step. However, as we found out later, desalting is not strictly necessary when using a $\mathrm{CHN}$ analyzer to combust samples.

The advantages of HPLC techniques over low-pressure chromatography are better separation, high reproducibility of retention times and thus direct identification of peaks, contant monitoring, and much shorter extraction times.

Theoretically, bone contamination during diagenesis can be eliminated as a source of erroneous bone datings by extracting and comparing individual amino acids. Only laboratory procedures, consisting of controllable factors, in principle, determine sample contamination.

The approach described here enables us to use chemically well-defined sample materials, $i e$, amino acids, instead of more uncontrollable collagen extracts. The same results may be obtained by the possible extraction of well-preserved (hydrophobic) proteins (Gillespie 1989). The comparison of different amino acids from one bone sample presents new opportunities in the evaluation of bone radiocarbon ages and stable isotope data for paleodietary reconstruction or for the study of isotope fractionation effects in biosynthetic processes.

\section{ACKNOWLEDGMENTS}

The investigations were supported by the Foundation for Archaeological Research (ARCHON) of the Netherlands Organization for Scientific Research (NWO). We would like to thank A T Bijma for her assistance with the HPLC separations. We thank Dr D E Nelson who provided the $1700 \mathrm{BP}$ bone sample, and $\mathrm{Dr} \mathrm{J}$ van der Plicht for critically reading the manuscript. The hospitality of the Biochemical Laboratory of Groningen State University and the advice of its staff are gratefully acknowledged. 


\section{REFERENCES}

Bornstein, P and Traub, W 1979 The chemistry and biology of collagen. In Neurath, H and Hill, R L, eds, The Proteins, vol IV. New York, Academic Press.

Brown, TA, Nelson, DE, Vogel, JS and Southon, JR 1988 Improved collagen extraction method by modified Longin method. Radiocarbon 30(2): 171-177.

DeNiro, MJ and Weiner, S 1988a Chemical, enzymatic and spectroscopic characterization of "collagen" and other organic fractions from prehistoric bones. Geochim et Cosmochim Acta 52: 2197-2206.

DeNiro, MJ and Weiner, S $1988 \mathrm{~b}$ Use of collagenase to purify collagen from prehistoric bones for stable isotope analysis. Geochim et Cosmochim Acta 52: 2425-2431.

Dungworth, G, Vincken, NJ and Schwartz, AW 1974 Compositions of fossil collagens: Analysis by gas-liquid chromatography. Comp Biochem Physiol 47B: 391-399.

El-Daoushy, MFAF, Olsson, IU and Oro, FH 1978 The EDTA and $\mathrm{HCl}$ methods of pretreating bones. Geol Fören Stockh Förh 100: 213-219.

Gaebler, OH, Vitti, TG and Vukmirovich, R 1966 Isotope effects in metabolism of ${ }^{14} \mathrm{~N}$ and ${ }^{15} \mathrm{~N}$ from unlabeled dietary proteins. Can Jour Biochem 44: 1249-1257.

Gillespie, R 1986 Chemical isotope dilution for ${ }^{14} \mathrm{C}$ AMS and the potential for GC/AMS. Radiocarbon 28(3): 1065 1067.

1989 Fundamentals of bone degradation chemistry: Collagen is not "the way". In Long, A, and Kra, RS, eds, Internatl ${ }^{14} \mathrm{C}$ conf, 13th, Proc. Radiocarbon 31(3): 239-246, in press.

Gillespie, R and Hedges, REM 1983 Sample chemistry for the Oxford high energy mass spectrometer. In Stuiver, M and $\mathrm{Kra}$, RS, eds, Internatl ${ }^{14} \mathrm{C}$ conf, 11th, Proc. Radiocarbon 25: 771-774.

Gillespie, R, Hedges, REM and Wand, JO 1984 Radiocarbon dating of bone by accelerator mass spectrometry. Jour Archaeol Sci 11: 165-170.

Gurfinkel, DM 1987 Comparative study of the radiocarbon dating of different bone collagen preparations. Radiocarbon 29(1): 45-52.

Hare, PE and Estep, MLF 1983 Carbon and nitrogen isotopic composition of amino acids in modern and fossil collagens. Carnegie Inst Washington Yrbk 82: 410-414.

Hedges, REM and Law, IA 1989 The radiocarbon dating of bone. Appl Geochem 4: 249-253.

Hedges, REM, Law IA, Bronk, CR and Housley, RA 1989 The Oxford accelerator mass spectrometry facility: Technical developments in routine dating. Archaeometry 31(2): 99-113.

Ho, TY, Marcus, LF and Berger, R 1969 Radiocarbon dating of petroleum-impregnated bone from tar pits at Rancho La Brea, California. Science 164: 1051-1052.

Joseph, MH and Marsden, CA 1986 Amino acids and small peptides. In Lim, CK, ed, HPLC of small molecules, a practical approach. Oxford, IRL Press.

Klinken, van, GJ, 1989 Note on the isolation of single amino acids from fossil bone. Appl Geochem 4(3): 271.

Longin, R 1971 New method of collagen extraction for radiocarbon dating. Nature 230: 241-242.

Macko, SA, Estep, MLF, Hare, PE and Hoering, TC 1983 Stable isotopic composition of individual amino acids isolated from cultured microorganisms. Carnegie Inst Washington Yrbk 82: 404-410.

Macko, SA, Fogel, ML, Hare, PE and Hoering, TC 1987 Isotopic fractionation of nitrogen and carbon in the synthesis of amino acids by microorganisms. Chem Geol (Isot Geosci Sec) 65: 79-92.

Mook, WG 1984 Archaeological and geological interest in applying ${ }^{14} \mathrm{C}$ AMS to small samples. Nuclear Instruments \& Methods B5: 297-302.

Moore, S and Stein, WH 1951 Chromatography of amino acids on sulphonated polystyrene resins. Jour Biol Chem 192: 663-667.

Olsson, IU, El-Daoushy, MFAF, Abd-El-Mageed, AI and Klasson, M 1974 A comparison of different methods for pretreatment of bones. Geol Fören Stockh Förh 96: 171-181.

Piez, KA 1984 Molecular and aggregate structure of the collagens. In Piez, KA and Reddi, AH, eds, Extracellular matrix biochemistry. New York, Elsevier.

Ramachandran, GN and Reddi, AH 1976 Biochemistry of collagen. New York, Plenum.

Schwarcz, HP, Hedges, REM and Ivanovich, M, eds, 1989 Internatl workshop on fossil bone, 1st, Proc. Appl Geochem 4(3): 211-342.

Stafford, TW Jr, Brendel, K and Duhamel, RC 1988 Radiocarbon, ${ }^{13} \mathrm{C}$ and ${ }^{15} \mathrm{~N}$ analysis of fossil bone: Removal of humates with XAD-2 resin. Geochim et Cosmochim Acta 52: 2197-2206.

Stafford, TW Jr, Duhamel, RC, Haynes, CV Jr and Brendel, K 1982 The isolation of proline and hydroxyproline from fossil bone. Life Sci 31: 931-938.

Stafford, TW Jr, Jull, AJT, Brendel, K, Duhamel, RC and Donahue, D 1987 Study of bone radiocarbon dating accuracy at the University of Arizona NSF accelerator facility for Radioisotope analysis. Radiocarbon 29(1): 24-44. 
Taylor, RE 1980 Radiocarbon dating of Pleistocene bone: Toward criteria for the selection of samples. In Stuiver, M and Kra, RS, eds, Internatl ${ }^{14} \mathrm{C}$ conf, 10th, Proc. Radiocarbon 22(3): 969-979.

1987 AMS ${ }^{14} \mathrm{C}$ dating of critical bone samples: Proposed protocol and criteria for evaluation. Nuclear Instruments \& Methods B29: 159-163.

Wand, JO (ms) 1981 Microsample preparation for radiocarbon dating. PhD dissert, Oxford Univ. 